\title{
ANÁLISE PATOLÓGICA EM OBRAS DE ARTE ESPECIAIS NA CIDADE DE SOBRAL-CE
}

\author{
RODRIGUES JÚNIOR, F. AVELAR \\ Graduado em Engenharia Civil \\ Universidade Estadual Vale do Acaraú \\ Ceará; Brasil \\ eng.avelarjunior@hotmail.com
}

\author{
ERIK DA SILVA, ANTÔNIO \\ Acadêmico de Engenharia Civil \\ Universidade Estadual Vale do Acaraú \\ Ceará; Brasil \\ eriksilva100@outlook.com
}

\author{
CARNEIRO, INARA LISSA \\ Acadêmica de Engenharia Civil \\ Universidade Estadual Vale do Acaraú \\ Ceará; Brasil \\ narinha_carneiro@hotmail.com
}

\author{
PARENTE LINHARES, P. ROBSON \\ Graduado em Engenharia Civil; \\ Universidade Estadual Vale do Acaraú \\ Ceará; Brasil \\ engpaulorobson@hotmail.com
}

\section{RESUMO}

É bastante notório que as pontes, ou Obras de Arte Especiais (OAE's), são estruturas de engenharia que apresentam como principal finalidade a transposição de vales ou trechos que apresentam cursos d'água. Essas estruturas são de grande importância para a circulação de veículos pelas vias, porém, após construídas, grande parte dessas obras não recebe nenhum tipo de inspeção ou manutenção preventiva, favorecendo o surgimento de manifestações patológicas e minimizando a vida útil das mesmas. Este trabalho de pesquisa foi desenvolvido com o objetivo de estudar as principais manifestações presentes em pontes no município de Sobral-CE, analisando-se, de maneira objetiva, as possíveis causas e soluções para as patologias encontradas e consideradas mais relevantes. Foi utilizada uma pesquisa bibliográfica exploratória, aliada a uma pesquisa de campo, com inspeções in loco, promovendo a análise visual dos elementos constituintes das pontes e realização do levantamento das principais patologias encontradas na estrutura, com o propósito de servir de embasamento técnico para a realização de terapias. Esperava-se que as principais patologias fossem apenas fissuras ou fendas, porém, por meio das vistorias, foram constatados problemas maiores, como exposição de armaduras, desagregação de concreto, eflorescências, drenos inapropriados e inconformidades nas juntas de dilatação. Por fim, espera-se alcançar dados fidedignos quanto aos aspectos supracitados e alertar aos órgãos competentes os problemas de degradação das pontes, para que os responsáveis, por meio de manutenções periódicas, possam garantir a vida útil das mesmas, não oferecendo riscos aos usuários.

Palavras-chave: Pontes, Patologias, Manifestações, Inspeção, Manutenção.

\section{ABSTRACT}

It is quite well known that bridges, or Special Works of Art (OAEs), are engineering structures that have as their main purpose the transposition of valleys or stretches that have watercourses. These structures are of great importance for the circulation of vehicles on the roads, but after construction, most of these works do not receive any type of inspection or preventive maintenance, favoring the appearance of pathological manifestations and minimizing their useful life. This research work was developed with the objective of studying the main manifestations present in bridges in the city of Sobral-CE, objectively analyzing the possible causes and solutions for the pathologies found and considered most relevant. An exploratory bibliographic research was used, allied to a field research, with on-site inspections, promoting the visual analysis of the bridge's constituent elements and the survey of the main pathologies found in the structure, with the purpose of serving as a technical basis for the realization. of therapies. The main pathologies were expected to be just cracks or cracks, but through surveys major problems were found, such as reinforcement exposure, concrete breakdown, efflorescence, improper drainage, and nonconformity in the expansion joints. Finally, it is expected to reach reliable data on the above mentioned aspects and alert the competent bodies of the problems of bridge degradation, so that those responsible, through periodic maintenance, can ensure their useful life, offering no risks to users.

Keywords: Bridges, Pathologies, Manifestations, Inspection, Maintenance. 


\section{INTRODUÇÃO}

Este trabalho faz uma análise das manifestações patológicas em pontes de concreto armado, tomando, como estudo de caso, cinco pontes existentes na cidade de Sobral, Ceará. Conforme Giannini et al. (2014), a modernização e a reparação das estruturas de concreto armado devem ser reconhecidas como uma prioridade, porém, no Brasil, pelo que se pode perceber, não há tradição de manutenção preventiva em edificações e obras civis, por mais que estejam no foco de alto fluxo de pessoas e evidencie riscos quanto à segurança. Pode-se notar facilmente o descaso de obras públicas, onde o estado de conservação de pontes e viadutos se encontra bastante prejudicado pela ação do homem ou, principalmente, do tempo. Cabe destacar que esses tipos de casos são, de certo modo, constrangedores, já que a população acaba financiando indiretamente, por meio de impostos, a manutenção desses monumentos.

É aconselhável que, por meio de fiscalizações periódicas dos órgãos responsáveis, haja maior preocupação com as patologias geradas em obras públicas, havendo uma melhor conservação dos equipamentos e evitando gastos maiores no futuro, já que os custos com manutenção são mínimos diante dos transtornos e estragos de uma estrutura que já se encontra comprometida. Uma maior organização e preocupação preventiva pode proporcionar uma maior segurança aos usuários e gerar mais economia para os setores afins.

As pontes de concreto armado costumam apresentar problemas comuns de corrosão das armaduras em suas vigas, pilares e tabuleiro. Portanto, com isso, surge a importância de analisar esse problema de maneira detalhada, pois o tratamento do mesmo possui influência direta na durabilidade da estrutura. Além deste, existem problemas como os de desagregação do concreto, eflorescências e inconformidades nas juntas e drenos, que também são consideradas patologias prejudiciais e apresentam efeitos maléficos no comportamento de obras rodoviárias.

As pontes de concreto armado normalmente se degradam devido a qualidade dos materiais empregados, defeitos de construção, exposição a ambientes agressivos, cargas excessivas, falta de ductilidade e envelhecimento. A diferenciação entre suas principais causas de deterioração torna-se meramente qualitativa, tendo em vista que os mecanismos supracitados podem atuar em sinergia (OMAR ; NEHDI, 2018).

Durante os estudos de caso, pode-se notar a presença de patologias com diferentes graus de risco, todas evidenciando serem resultado da evolução de pequenas manifestações patológicas. Tal fato justifica-se no supracitado descaso com as obras civis de grande porte.

A falta de manutenção faz com que pequenas manifestações patológicas, que teriam baixo custo de recuperação, evoluam para situações de desempenho insatisfatório com ambientes insalubres, de deficiente aspecto estético, de possível insegurança estrutural e de alto custo de recuperação (ANTONIAZZI, s.d.).

Neste contexto, o presente trabalho tem por objetivo identificar as manifestações patológicas e analisar os principais danos presentes em cinco pontes de concreto armado por meio de inspeções visuais in loco. De modo a contribuir para o conhecimento do estado atual de danos destas estruturas e fornecer informações que possam ser utilizadas em possíveis reparos, visando o restabelecimento das condições funcionais e estruturais.

\section{ESTUDOS DE CASO}

A cidade de Sobral localiza-se na região Noroeste do Ceará e Nordeste do Brasil, sendo ligada a capital Fortaleza através da rodovia BR-222, que liga, ainda, o estado do Ceará ao Piauí, do Maranhão e do Pará. As pontes utilizadas como objetos de estudo neste trabalho são de relevância para o patrimônio e desenvolvimento desta cidade, quais sejam: Pontes sobre o rio Oiticica (PT1 e PT2), Ponte Pref. José Euclides (PT3), Ponte Othon de Alencar (PT4) e Ponte sobre o rio Jaibaras (PT5), todas servindo de via de circulação de veículos de pequeno à grande porte, transportando pessoas e mercadorias.

A análise realizada nas pontes consistiu em uma vistoria simples, com registro fotográfico das eventuais manifestações patológicas. Por falta de equipamentos e dificuldade de acesso aos locais, não foi possível especificar, de maneira mais detalhada, as causas de algumas manifestações registradas. 


\subsection{Ponte sobre o rio Oiticica}

As pontes sobre o rio Oiticica, ilustradas nas Figuras 1 e 2, estão localizadas na Avenida Senador Fernandes Távora. Ambas foram construídas na década de 90, chegando a passar por pequenas reformas no ano de 2017, sendo constituídas de sistemas estruturais em concreto armado e apresentando cerca de $50 \mathrm{~m}$ de comprimento, se distinguindo devido as seguintes características de construção:

- PT1: 14 m de largura, 02 passeios para pedestres (sendo 01 metálico), tabuleiro sustentado por 04 pilares (ponte-viga) e o aterro de acesso não apresenta contenção;

- PT2: 12 m de largura, 01 passeio para pedestres (metálico), 01 pilar parede, tabuleiro sustentado por uma viga parede, além de 04 longarinas protendidas e 04 transversinas, apresentando um muro de contenção no aterro de acesso.

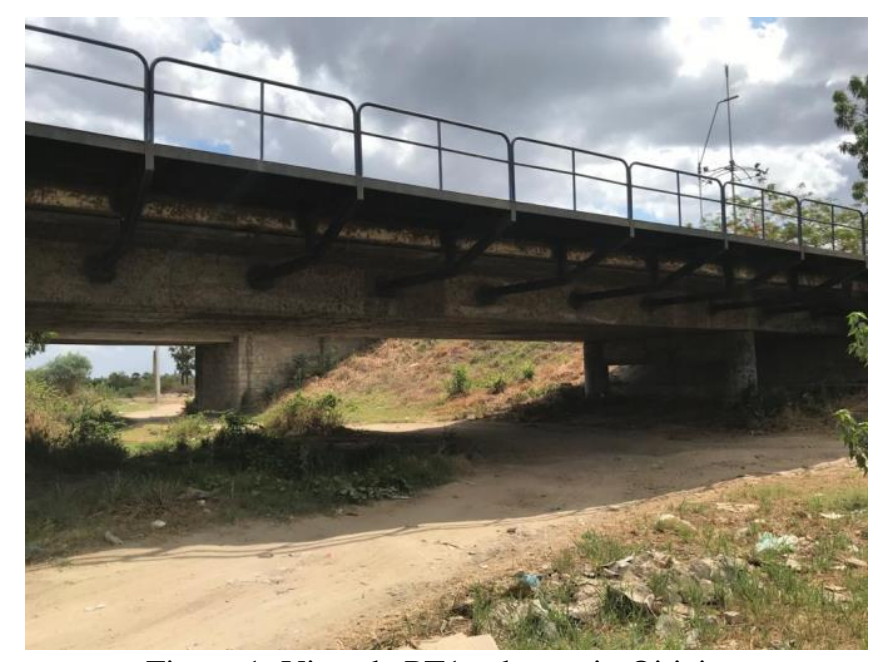

Figura 1: Vista da PT1 sobre o rio Oiticica.

Fonte: Autores (2020)

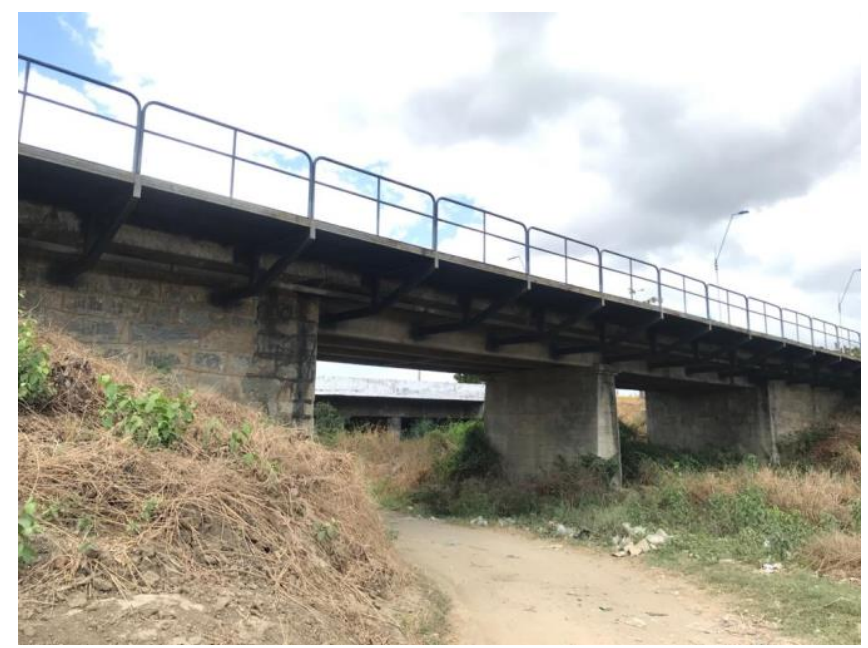

Figura 2: Vista da PT2 sobre o rio Oiticica.

Fonte: Autores (2020)

\subsection{Ponte Pref. José Euclides}

A ponte PT3, ilustrada na Figura 3, inaugurada no ano 2000, tem uma grande importância para a cidade, tendo em vista que sua construção diminuiu a distância entre os moradores das margens esquerda e direita do Rio Acaraú. Alem disso, essa ponte configurou uma nova alternativa de tráfego para os moradores dos bairros Dom Expedito e Sinhá Saboia, assim como para os trabalhadores do Distrito Industrial, tendo como consequência a diminuição do tempo de deslocamento para o trabalho (VENÂNCIO, 2012). 
A ponte PT3 está localizada na Avenida Monsenhor Aluísio Pinto sobre o Rio Acaraú, em Sobral, Ceará, e tem, aproximadamente, 360 metros de comprimento por 12 metros de largura. Ela conta com sistema rodoviário sobre ela composto por duas faixas em sentido duplo. Quanto ao tipo de material, é uma ponte de concreto armado. O sistema estrutural da superestrutura é composto por vigas e com laje maciça. Quanto ao desenvolvimento planimétrico, ela pode ser considerada uma ponte reta, apresentando arcos em suas laterais, embelezando seu detalhe arquitetônico.

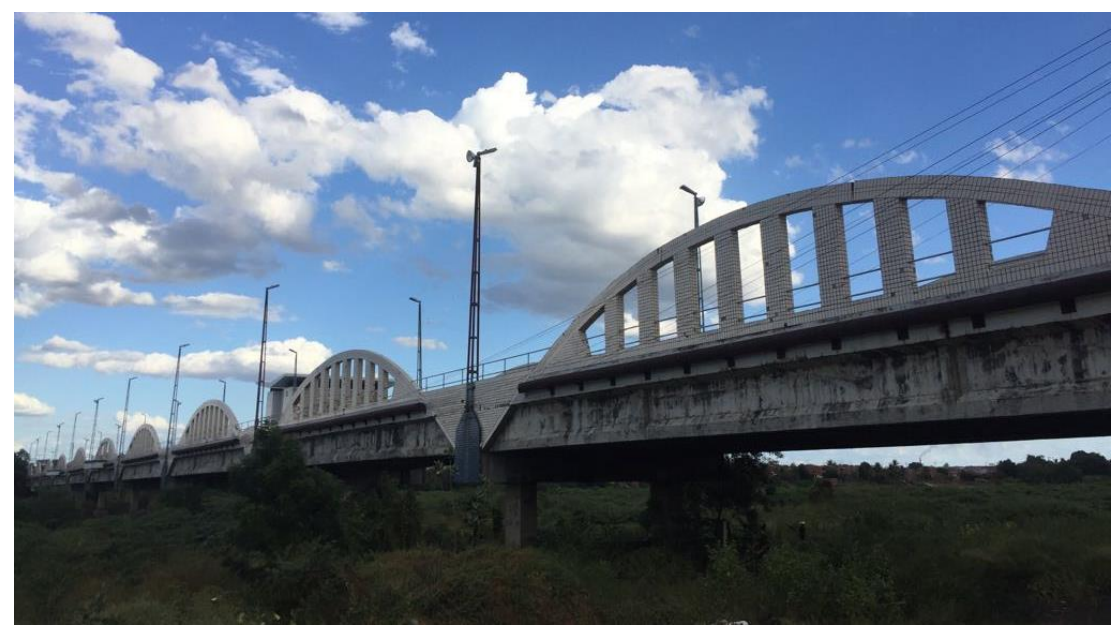

Figura 3 - Vista atual da Ponte Pref. José Euclides.

Fonte: Autores (2020)

\subsection{Ponte Othon de Alencar}

A ponte PT4 está localizada na Avenida Fernandes Távora, sobre o Rio Acaraú e tem, aproximadamente, 255 metros de comprimento por cerca de 22 metros de largura. Ela foi construída, segundo diz uma placa indicativa sobre a ponte, por volta de 1935, e possui um sistema rodoviário e uma linha férrea sobre ela. Segundo informação, a ponte passou por uma duplicação do sistema rodoviário por volta de meados de 2004, passando a apresentar duas faixas em sentido único.

Levando em consideração o tipo de material constituinte, a ponte é classificada como uma ponte de concreto armado. $\mathrm{O}$ sistema estrutural da superestrutura é composto por vigas e laje maciça e, baseando-se no desenvolvimento planimétrico, pode ser considerada uma ponte reta.

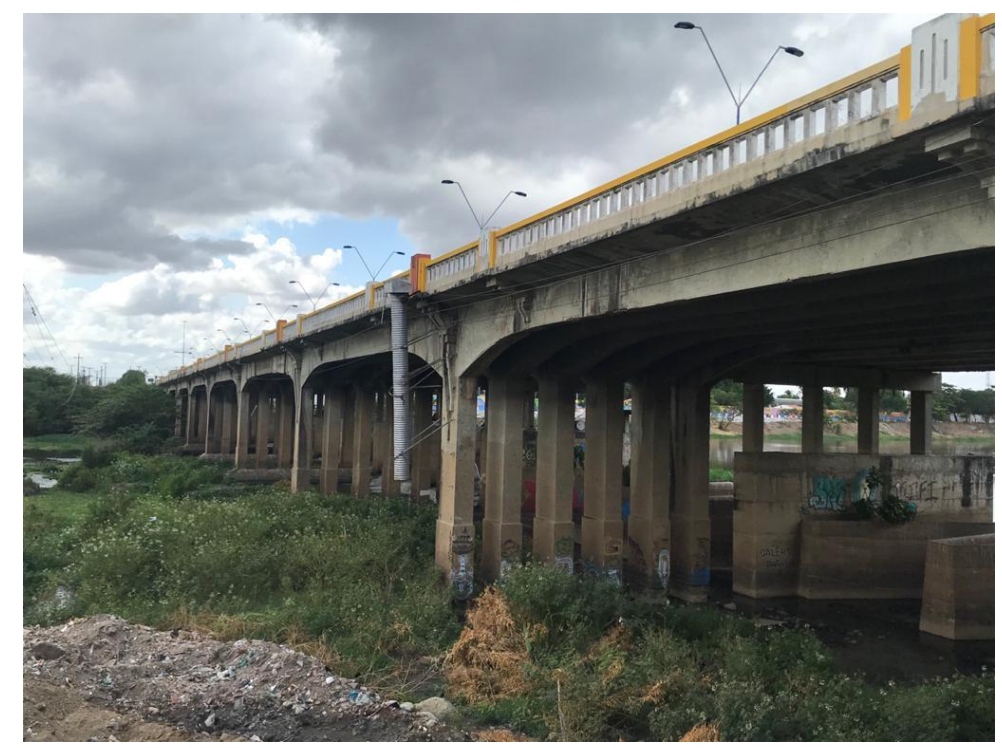

Figura 4 - Vista atual da Ponte Othon de Alencar.

Fonte: Autores (2020) 


\subsection{Ponte sobre o rio Jaibaras}

A ponte PT5 está localizada na BR-222, próximo ao bairro Sumaré, sendo de essencial importância para a circulação de veículos que se direcionam para a Serra da Ibiapaba. A PT5 tem como finalidade a transposição sobre o Rio Jaibaras e tem, aproximadamente, 90 metros de comprimento por cerca de 13 metros de largura. O sistema rodoviário é composto por duas faixas em sentido duplo. Por falta de informações fornecidas pelos órgãos públicos, não foi possível coletar mais dados específicos.

Baseado no que foi observado nas visitas, levando em consideração o tipo de material constituinte, a ponte é classificada como uma ponte de concreto armado. O sistema estrutural da superestrutura é composto por vigas e laje maciça e, baseando-se no desenvolvimento planimétrico, assim como as outras, é considerada uma ponte reta.

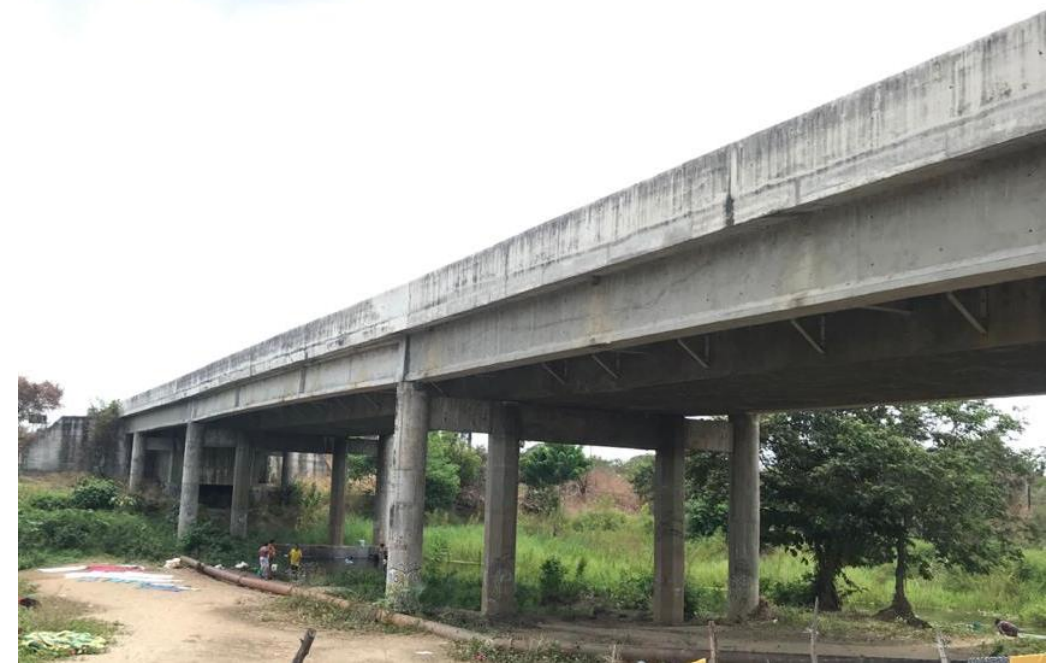

Figura 5 - Vista atual da Ponte sobre o rio Jaibaras.

Fonte: Autores (2020)

\subsection{Procedimentos metodológicos}

A metodologia utilizada neste trabalho foi uma pesquisa bibliográfica exploratória, aliada a uma pesquisa de campo em pontes existentes na cidade de Sobral, Ceará, como estudo de caso, onde foram feitos registros fotográficos das diversas manifestações patológicas encontradas. Este trabalho foi desenvolvido baseado na caracterização e especificação dos elementos constituintes das pontes, citando suas classificações e relatando as patologias mais visíveis nesses elementos de transposição.

Além disso, buscou-se utilizar como base a Norma de Inspeção Predial Nacional elaborada pelo Instituto Brasileiro de de Avaliações e Perícias de Engenharia (IBAPE), analisando-se os casos encontrados e reconhecendo as soluções emergenciais que devem ser tomadas em cada caso. Situações como as encontradas se encaixam caracteristicamente no estado crítico, apresentando risco de provocar danos contra a saúde e segurança das pessoas e do meio ambiente, perda excessiva de desempenho e funcionalidade, causando possíveis paralisações, aumento excessivo de custo de manutenção e recuperação, além de comprometimento sensível de vida útil (IBAPE, 2012).

\section{RESULTADOS E DISCUSSÕES}

Nesse tópico será citado as patologias encontradas em cada caso analisado, buscando-se mostrar as possíveis causas e citar os devidos estágios de risco baseados nas manifestações presentes nas obras de arte. Cabe destacar, que as patologias analisadas foram as mais visíveis e consideradas a mais preocupantes para a vida útil de cada monumento. 


\subsection{Análise das manifestações da PT1}

Por meio das inspeções e visitas realizadas, pode-se notar claramente que os 04 pilares da referida ponte apresentam sérias manifestações patológicas, como corrosão das armaduras na base do pilar, desagregação do concreto, fissuras e trincas, como pode ser visualizado nas Figuras 6 e 7 a seguir. A possível causa dessas manifestações podem estar diretamente relacionadas com o tipo de concreto utilizado na época da construção, supostamente formado por compostos mais porosos. Pode-se observar que as armaduras em questão já apresentam considerável perda de seção, possibilitando uma redução na vida útil dessa obra de arte. O estado do monumento já pode ser considerado crítico, apresentando urgência na execução de manutenção.

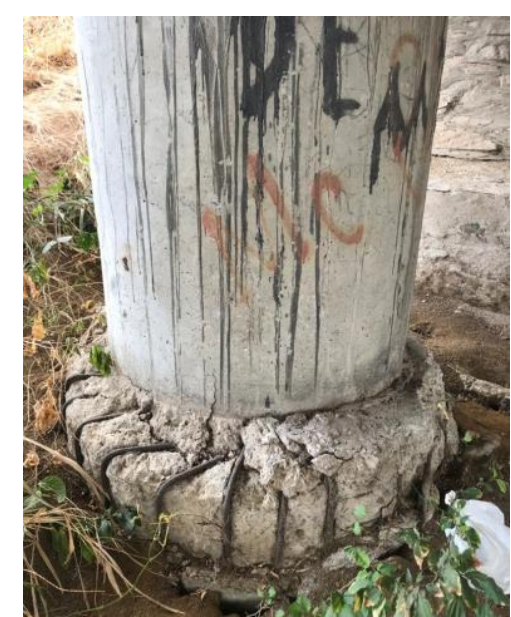

Figura 6 - Detalhe da base do pilar. Fonte: Autores (2020)

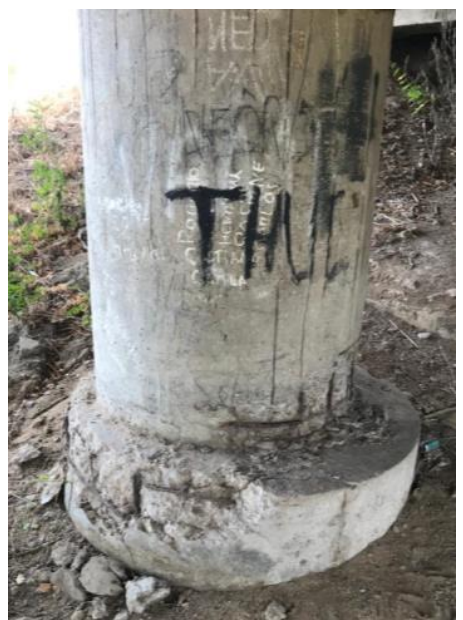

Figura 7 - Detalhe da base do pilar.

Fonte: Autores (2020)

Segundo Souza e Ripper (1998), o processo de desagregação é caracterizado pelo ato de separação física de placas ou fatias de concreto, com perda de rigidez, perda da capacidade de entrosamento entre os agregados e desvio da função ligante do cimento. Consequentemente, elementos estruturais com seções de concreto desagregado tendem a diminuir, local ou inteiramente, a capacidade de resistir aos esforços que a solicitam.

Além das manifestações presentes nos pilares, pode-se notar também a grande inconformidade dos drenos presentes no decorrer da ponte. Devido esses componentes não estarem executando a sua funcionalidade de maneira correta, nota-se claramente o surgimento de manchas de umidade na estrutura do tabuleiro, ocasionando fenômenos conhecidos como lixiviação e eflorescência, consideradas as principais manifestações iniciais decorrentes em estruturas de concreto armado. As Figuras 8 e 9 caracterizam as inconformidades citadas.

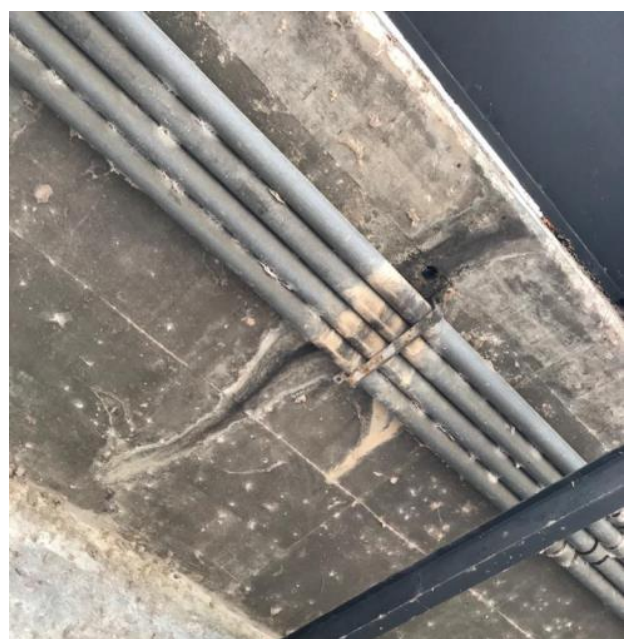

Figura 8 - Mancha de umidade causada por dreno inconforme. Fonte: Autores (2020)

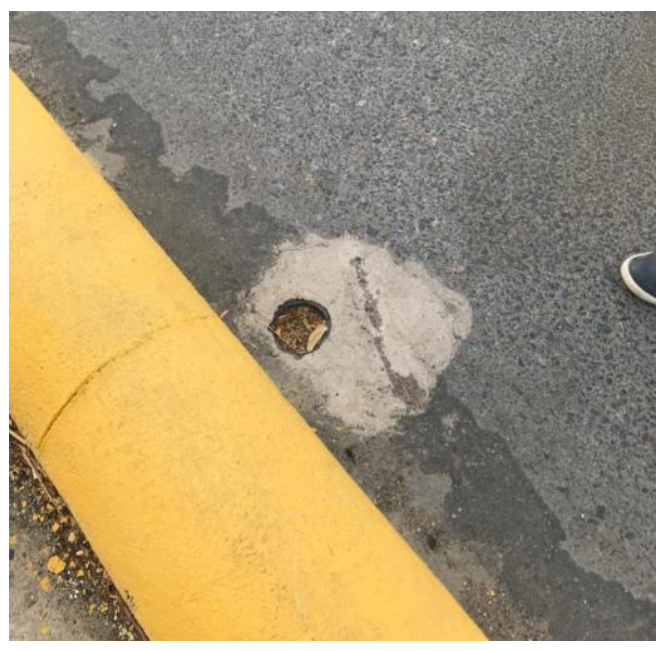

Figura 9 - Dreno obstruido. Fonte: Autores (2020) 
Segundo DNIT (2006), as eflorescências são provocadas quando águas puras com poucos ou nenhum íon de cálcio entram em contato direto com a pasta de Cimento Portland (CP). A lixiviação do hidróxido de cálcio do concreto, além da perda de resistência, provoca agressões visuais e estéticas nas estruturas de engenharia, já que o produto lixiviado interage com o $\mathrm{CO} 2$ presente no ar, ocasionando na precipitação de crostas brancas de carbonato de cálcio na superfície.

As eflorescência e lixiviações estão entre as patologias mais comuns em obras especiais de engenharia, ocasionando profunda degradação do concreto de elementos estruturais e também, na maioria das vezes, gerando a corrosão das armaduras. A medida preventiva para esse tipo de problema é haver a devida execução dos drenos, apresentando o devido transpasse em relação ao tabuleiro da ponte, e, também, haver as manutenções quanto as obstruções decorrentes. Além disso, deve-se ter o devido cuidado com a execução da impermeabilização dos elementos principais das obras, impedindo que a água seja transportada por percolação e atinja os setores internos do arranjo estrutural.

\subsection{Análise das manifestações da PT2}

Por meio da vistoria, pode-se notar claramente que a PT2 se trata de uma ponte consideravelmente mais nova que a ponte PT1. Porém, devido a falta de manutenção, a PT2 já apresenta manchas intensas de umidade em seu tabuleiro, acarretando no surgimento de armaduras expostas. As Figuras 10 e 11 mostram uma visão sobre a situação.

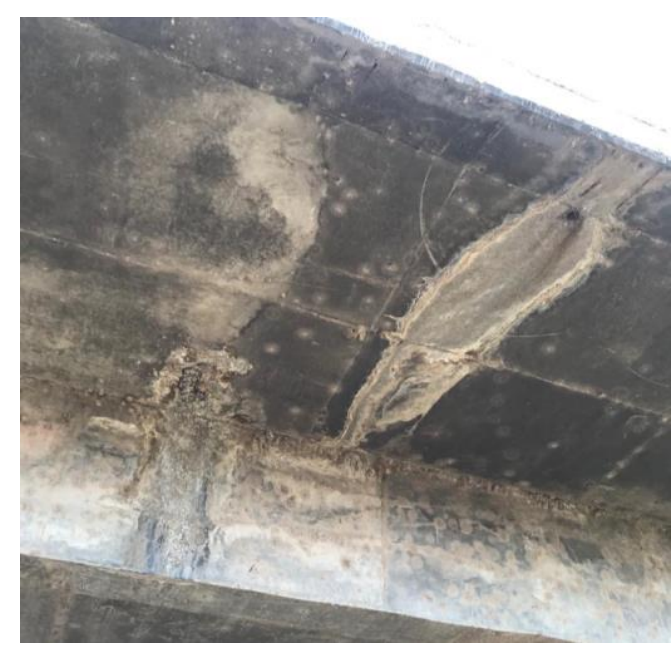

Figura 10 - Manchas de umidade intensas e surgimento de armadura exposta ao lado da longarina. Fonte: Autores (2020)

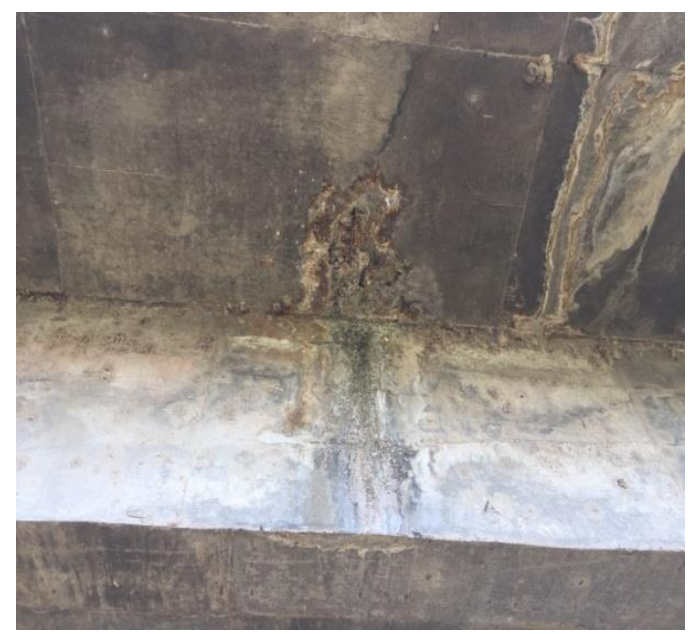

Figura 11 - Corrosão das barras do tabuleiro. Fonte: Autores (2020)

Assim como na PT1, a PT2 apresenta esses tipos de manifestações devido à má execução dos drenos e a ausência de manutenção ideal. $\mathrm{O}$ estado da ponte pode ser considerado de nível médio, provocando perda parcial de desempenho e funcionalidade da obra de arte. Cabe destacar que, pela intensidade das manifestações encontradas e o descaso por parte do órgão público, o nível das anomalias tendem a atingir o estágio crítico bem em breve.

Laner (2001) determina que, as falhas em instalações de drenagem são consideradas fatores preocupantes na degradação do concreto e das armações. Devido a esse fato, deve-se haver uma preocupação redobrada com suas execuções e inspeções, para que, assim, não haja acúmulo de água em pontos críticos, como por exemplo, encontros de apoio de vigas, nos caixões, nos encontros com tabuleiros, na pista de rolamento, nos aparelhos de apoio, entre outros.

\subsection{Análise das manifestações da PT3}

Por se tratar de uma ponte consideravelmente nova, felizmente, a PT3 não apresentou patologias relacionadas com corrosão ou exposição de armaduras. Porém, assim como as outras pontes apresentadas nesse estudo, notou-se muitas manchas de infiltrações em seus elementos estruturais e, além disso, percebeu-se grande parte de seus drenos obstruídos e/ou não executando a sua devida funcionalidade. As imagens a seguir caracterizam melhor algumas manifestações encontradas nessa obra de arte especial. 


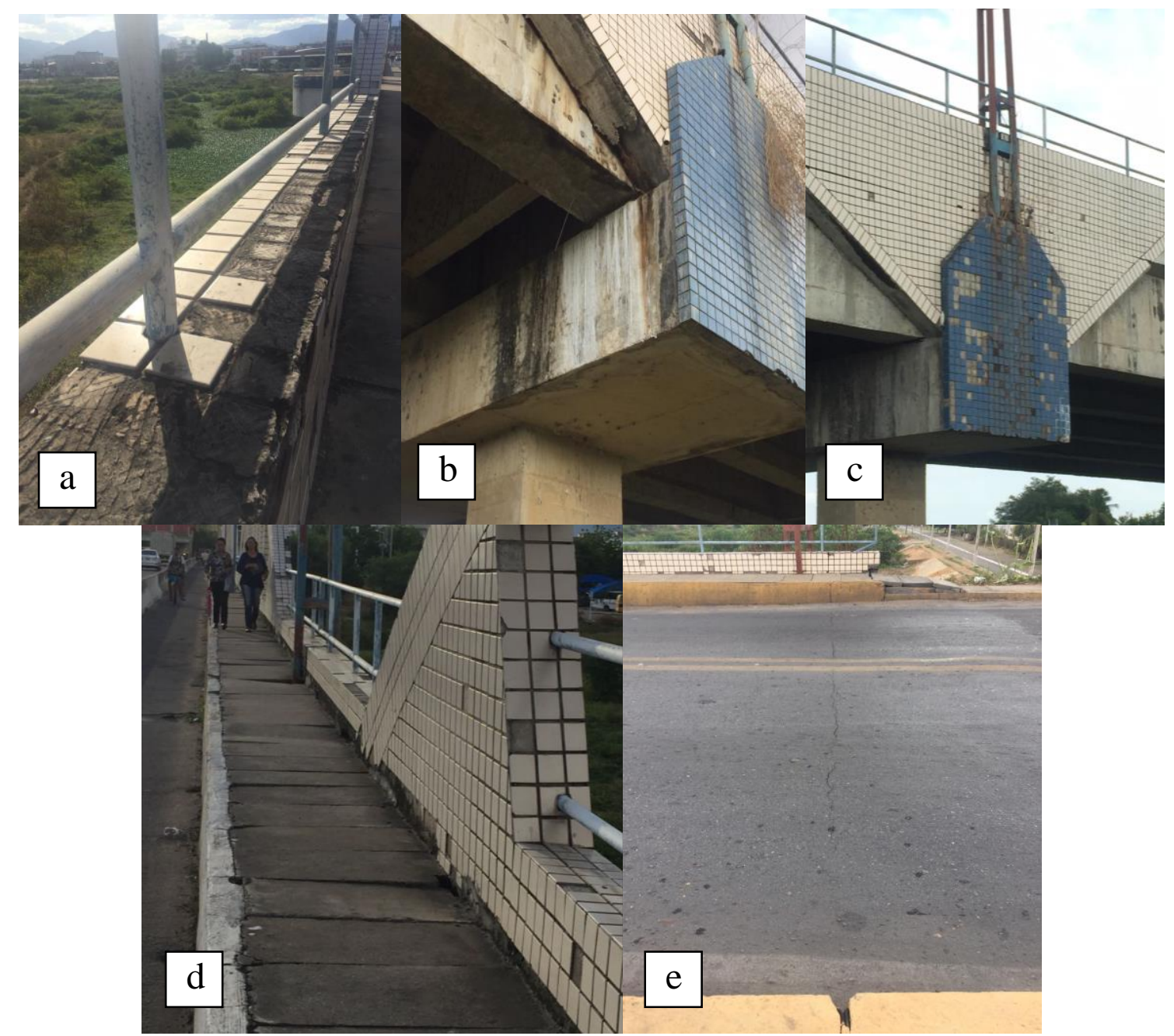

Figura 12 - Manifestações presentes na PT3: desplacamento de revestimento cerâmico (a e c), a presença de vegetação na estrutura (b e c), inconformidades no passeio (d) e inconformidades em juntas de dilatação (e).

Fonte: Autores (2020)

Pode-se observar claramente que, apesar de não ter surgido ainda nenhum caso de exposição e corrosão de armaduras na estrutura da mesma, conclui-se que a situação da ponte é emergencial, já que os inúmeros casos de infiltração, perda de revestimento cerâmico e drenos inconformes prejudicam constantemente sua situação, minimizando cada vez mais a sua durabilidade.

Diferente das outras pontes citadas, a PT3 apresentou algumas manifestações inusitadas. Pode-se notar que em seu passeio existem algumas inconformidades que prejudicam a circulação dos pedestres, além de favorecer o acúmulo de águas pluviais no interior da ponte, devido as placas pré-moldadas de concreto estarem danificadas. Outra patologia observada foi a presença de juntas de dilatação desgastadas, sendo necessário uma intervenção de imediato nas mesmas.

\subsection{Análise das manifestações da PT4}

Dentre todas as pontes analisadas neste estudo de caso, a PT4 pode ser considerada a ponte que apresenta o estado mais crítico e emergencial. Nesta obra de arte foram encontradas praticamente todas as manifestações presentes nas outras pontes estudadas, constatando um grande índice de armaduras expostas e manchas de umidade decorrentes em grande parte de sua estrutura. As imagens a seguir caracterizam algumas situações encontradas. 


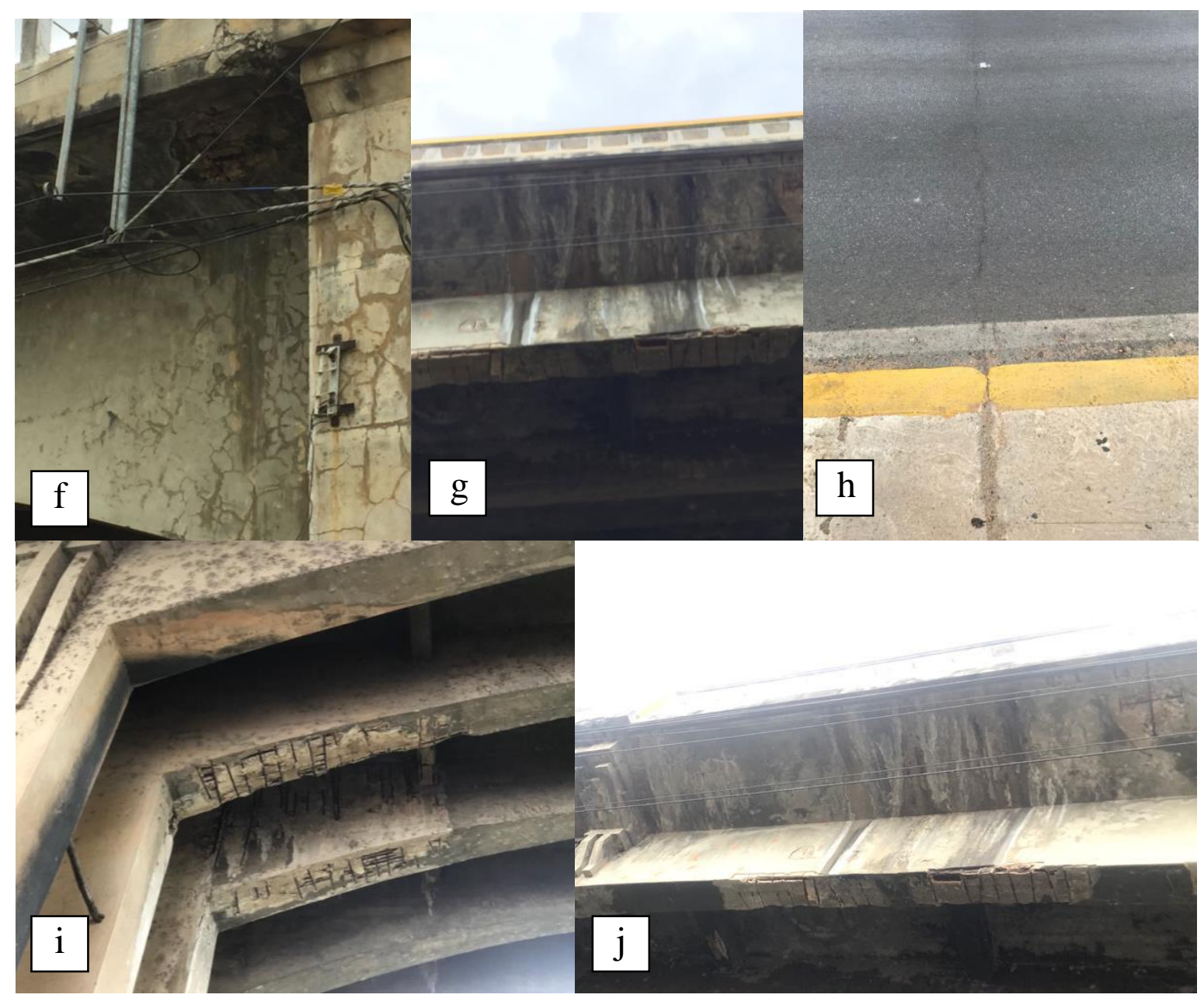

Figura 13 - Manifestações presentes na PT4: fissuras em forma de mapas (f), manchas de umidade (g e j), inconformidades em juntas de dilatação (h) e grande incidência de armaduras expostas com corrosão (i e j).

Fonte: Autores (2020)

O processo de corrosão nas estruturas de concreto armado ocorre, principalmente, quando as obras especiais de engenharia se encontram em meios mais agressivos, quando o concreto apresenta alto índice de porosidade, elevada capilaridade, erro na execução do cobrimento ideal para as armaduras, má escolha dos materiais de construção e alto índice de fissuras. O caso da PT4 caracteriza bem esse tipo de situação, tratando-se de uma obra com cerca de 85 anos de idade e sem sofrer manutenções periódicas, sua vida útil está totalmente prejudicada, apresentando estágio crítico e podendo ocasionar danos contra a saúde e segurança das pessoas e do meio ambiente.

Segundo Saliba Júnior (2008), o fenômeno da corrosão de armaduras é mais comum do que qualquer outro fenômeno de degradação das estruturas de concreto armado, prejudicando-as tanto do ponto de vista estético, quanto do ponto de vista de segurança, além de acarretar em custos elevados com a recuperação.

\subsection{Análise das manifestações da PT5}

A PT5, por se tratar de uma ponte localizada no percurso de circulação da BR-222, apresenta uma imensa importância para os seus transeuntes e é responsável por suportar grandes solicitações, principalmente devido o constante tráfego de veículos pesados nessa via. Esta ponte aparenta ser bastante nova, apresentando como principal finalidade a transposição sobre o rio Jaibaras.

Pelo que se pode notar na vistoria, foram encontradas algumas manifestações decorrentes, tanto na parte superior como na parte inferior da ponte. As imagens a seguir caracterizam as situações encontradas. 


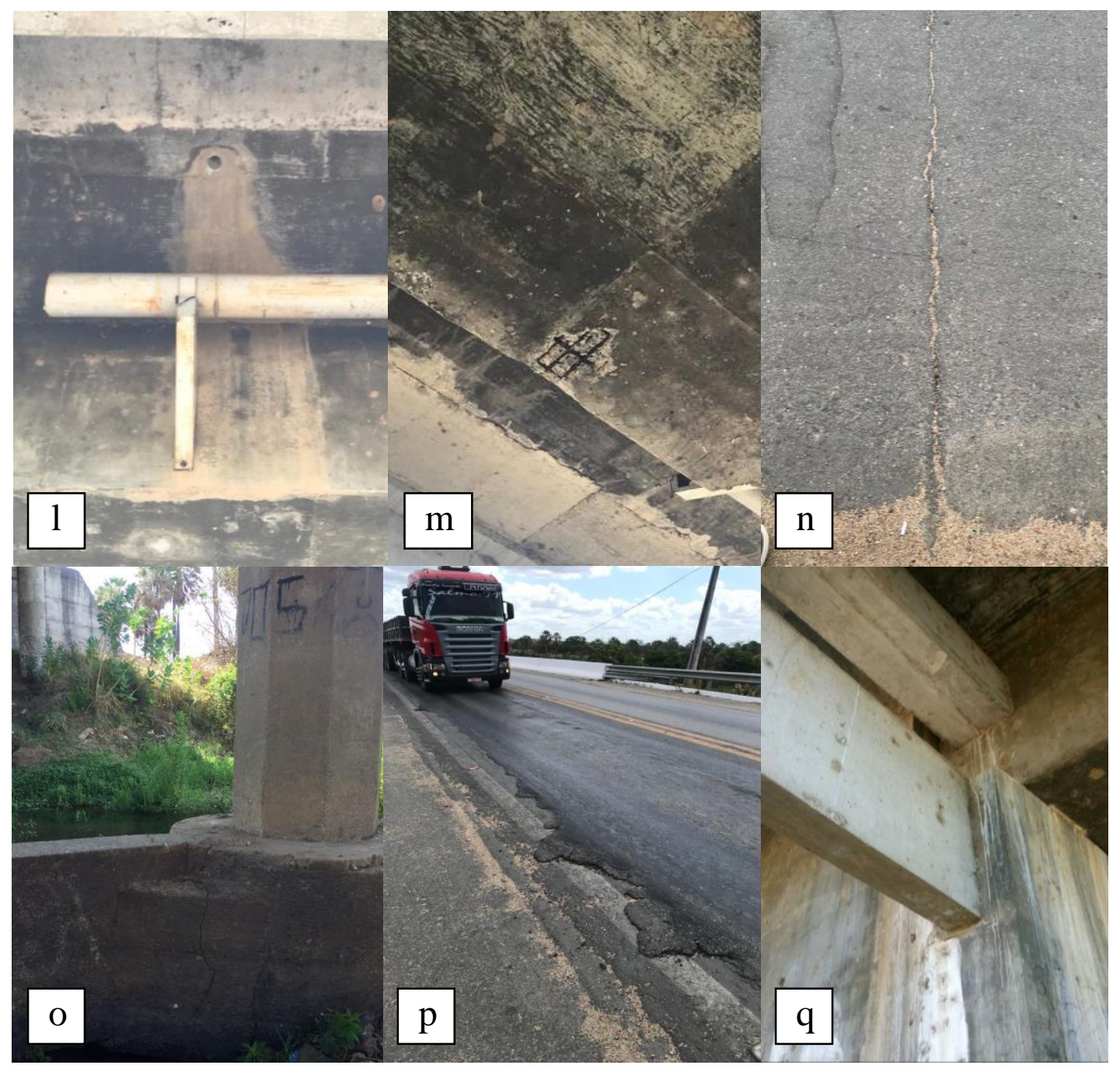

Figura 14 - Manifestações presentes na PT5: manchas de umidade (1 e q), armadura exposta no tabuleiro (m), inconformidades em junta de dilatação (n), fissuras na infraestrutura (o) e escorregamento do pavimento (p).

Fonte: Autores (2020)

Notou-se, caracteristicamente, que a parte inferior da PT5 apresentava muitas manchas de coloração branca, denotando o fenônemo conhecido como lixiviação do concreto. Além das manchas de umidade, observou-se casos de armaduras expostas no tabuleiro, inconformidades em juntas de dilatação e drenos não apresentando o devido transpasse em relação ao tabuleiro, acarretando no contato direto entre as águas pluviais e os elementos constituintes da obra de arte.

Diferente das outras pontes citadas, a PT5 também apresentou inconformidades no pavimento asfáltico, fenômeno conhecido como escorregamento. Balbo (1997) descreve escorregamento como sendo um deslocamento no sentido transversal da mistura asfáltica, ocorrendo geralmente em faixas solicitadas por veículos comerciais e atribui sua origem a imprimação inadequada do revestimento sobre a camada inferior, inadequada compressão da mistura asfáltica antes da liberação da pista para o tráfego, a viscosidade inadequada do cimento asfáltico para as condições de uso e ao excesso de ligante na mistura.

\section{CONCLUSÕES}

Através das inspeções realizadas nas cinco pontes, realizando-se vários registros fotográficos, pode-se concluir que as manchas de umidade, inconformidades nas juntas, desagregação de concreto e corrosão nas armaduras dos elementos estruturais são as manifestações patológicas mais incidentes.

Os inúmeros casos de patologias encontrados reforçam a urgência de uma intervenção imediata nessas pontes. As terapias necessárias devem ser realizadas por profissionais capacitados, para que, assim, seja definido o melhor método 
de recuperação e/ou reforço nos elementos danificados. Cabe destacar também, a importância da criação de um plano de manutenção periódica, podendo evitar, facilmente, a intensificação e a proliferação de patologias graves nas estruturas especiais de engenharia.

Tomando-se como base as situações consideradas mais críticas, como encontrado na PT1 e PT4, apresentando desagregação de concreto e armaduras expostas com presença de corroção, recomenda-se, inicialmente, por meio de uma perícia, buscar as verdadeiras causas desses tipos de patologias. Porém, pode-se concluir que, nesses tipos de manifestações, deve-se executar uma análise da necessidade de aplicação de reforço estrutural (utilizado quando há perda de seção da armadura), além de promover a devida limpeza das barras, utilizar escoramento adequado e aplicar concreto de excelente qualidade, analisando a possibilidade de aplicação de materiais impermeabilizantes ou pintura adequada.

Analisando-se os casos com presença de manchas de umidade, como caracterizado em todas as pontes inspecionadas, aconselha-se observar o grau da patologia, promover a devida limpeza do local e avaliar qual a medida correta a se tomar. Casos mais simples que ainda não tenham prejudicado a estrutura da obra de arte, podem ser solucionados pela utilização de argamassas especializadas. Entretanto, como se notou em todos os casos estudados, o sistema de drenagem das pontes é o principal acarretador do acúmulo de umidade nos elementos estruturais, devendo ser executado de maneira correta, com seu devido transpasse em relação ao tabuleiro da ponte, e, além disso, passar por vistorias frequentes, evitando obstruções.

Em relação as juntas de dilatação, a maioria delas foi encontrada com alto índice de desgaste, não apresentando nenhuma indicação de manutenção recente. Por se tratarem de dispositivos, de certo modo, considerados caros e de substituição difícil e onerosa, esses elementos, na maioria das vezes, são executados de maneira incorreta ou dificilmente passam por manutenções. A falha de execução, fixação inadequada e falta de vedação entre seus componentes são os principais causadores de consequências danosas para as estruturas das obras especiais. Cabe destacar que os casos analisados necessitam urgentemente de correções, favorecendo a devida garantia da funcionalidade.

Por fim, por meio das visitas e inspeções realizadas nas pontes, espera-se alertar aos órgãos competentes sobre os problemas presentes nessas estruturas, para que os responsáveis, por meio de manutenções periódicas, possam garantir a vida útil das mesmas, não oferecendo riscos aos usuários. Estruturas como essas exercem funcionalidade primordial, sendo imprescindível a elaboração de um plano de manutenção periódico que garanta a sua plena conservação. 


\section{REFERÊNCIAS}

ANTONIAZZI, Juliana Pippi. Patologia da Construção: Abordagem e Diagnóstico. Monografia (Graduação em Engenharia Civil), Universidade Federal de Santa Maria, Rio Grande do Sul, s.d.

BALBO, J. T., Pavimentos Asfálticos - patologias e manutenção. São Paulo, Editora Plêiade, 1997.

DNIT, Departamento Nacional de Infraestrutura e Transportes. Patologias do concreto - Especificação de Serviço. Norma 090/2006 - ES. Rio de Janeiro, 2006.

GIANNINI, R. et al. Assessment of concrete strength combining direct and NDT measures via Bayesian inference. Engineering Structures, v. 64, p. 68-77, 2014.

IBAPE. Norma de inspeção predial nacional. São Paulo, 2012. Disponível em: http://ibapenacional.com.br/biblioteca/wp-content/uploads/2012/12/Norma-de-Inspeção-Predial-IBAPE-Nacional.pdf. Acesso em: 13 jan. 2020.

LANER, F. J. Manifestações Patológicas nos Viadutos, Pontes e Passarelas do Município de Porto Alegre. Porto Alegre, 2001.

OMAR, T. ; NEHDI, M. Condition Assessment of Reinforced Concrete Bridges: Current Practice and Research Challenges. Infrastructures, v. 3, p. 1-23, 2018.

SALIBA JUNIOR, C. C. Técnicas de recuperação de estruturas de concreto armado sob efeito da corrosão das armaduras. Universidade Federal de Minas Gerais. Belo Horizonte - MG, 2008.

SOUZA, V.; RIPPER, T. Patologia, Recuperação e Reforço de Estruturas de Concreto. - São Paulo: Pini, 1998.

VENÂNCIO, R. Travessias ribeirinhas: narrativas e práticas cotidianas. Cadernos do LEME, Campina Grande, v. 4, no 1, p. 47-66, 2012. 